\title{
Drinking water in traditional Persian medicine: Do's and don'ts
}

Majid Nimrouzi ${ }^{1}$, Babak Daneshfard ${ }^{2}$

${ }^{1}$ MD, MPH, Ph.D. of Traditional Persian Medicine, Assistant Professor, Research Center of Quran, Hadith and Medicine, Shiraz University of Medical Sciences, Shiraz, Iran

${ }^{2}$ MD, Ph.D. Candidate of Traditional Persian Medicine, Essence of Parsiyan Wisdom Institute, Phytopharmaceutical Technology and Traditional Medicine Incubator, Shiraz University of Medical Sciences, Shiraz, Iran

Type of article: Letter to Editor

\begin{abstract}
Water is the main component of our body and its balance is vital for maintaining normal physiology. Accordingly, adequate fluid intake in the daily diet is very important for a healthy life. Nevertheless, there is a controversy about what the suitable amount of water that we need to drink is. In this paper, we aimed to discuss this important issue based on the doctrine of traditional Persian medicine (TPM) and our clinical experience in a practical manner.
\end{abstract}

Keywords: Traditional Persian Medicine, Water, Water-Electrolyte Balance

\section{Dear editor,}

Traditional Persian Medicine (TPM) is considered as a medical school with a holistic approach to diagnosis and treatment (1). It is based on the experiments of Iranian scholars and physicians through more than 1000 years of scrutinized practice of medicine under the shadow of Hekmat or Islamic philosophy (1). Avicenna (980-1037 AD) is one of the most famed scholars and physicians in TPM (2). Canon of medicine, his great masterpiece in medicine has been a valuable source for all physicians who followed $(3,4)$. Avicenna and TPM sages believed that eating and drinking should be observed in attribution to all other daily activities either physical or mental (5). The stomach, according to the viewpoint of TPM sages, is the gateway for every disease, and should be kept by full observance in drinking and eating (1). Water plays the role of conveyor and it is not considered as a food. It facilitates the passage of the ingested food in the gastrointestinal (GI) tract and contributes in digestion, absorption and refreshing of the body organs as well as expelling the waste maters of different stages of food digestion and metabolism (6). However, fluid excess is harmful for the body as confirmed by recent studies. Water also plays a crucial role in the maintenance of homeostasis and comprises of about 70 percent of an adult's body weight; however, in few conditions including renal failure, heart failure, and end stage liver diseases, it should be consumed in a limited amount (7). Nevertheless, healthy adults drink water without any specified medical limitation and duly adjust it based on their thirst and physical conditions. TPM sages believe that drinking too much water leads to weakness of the GI tract that will eventually increase the risk of other body organs' disease and failure (8-10). Accordingly, rules of drinking should be observed if someone seeks a healthy life. Time, place, body constitution, habits, occupation, time interval with meals, physical activities, intercourse, and bath/sauna are important issues attributed to drinking water (8). Drinking water or watery foods such as fruits and juices are banned in the short interval after a meal or during the meal, except in small amounts in healthy young individuals who have hot constitution (Mezaj) and cannot tolerate thirst because of higher metabolism (11). Drinking water is also prohibited during or just after intense physical activities, intercourse, or bath/sauna. Moreover, it is recommended that after waking, drinking should be postponed for a while. The best time for drinking is in the time of true thirst in a healthy state. Drinking lukewarm or warm water for a long time weakens the GI tract. The water should be cool, of course not excessively, without the

\section{Corresponding author:}

Babak Daneshfard, Essence of Parsiyan Wisdom Institute, Phytopharmaceutical Technology and Traditional Medicine Incubator, Shiraz University of Medical Sciences, Shiraz, Iran.

Tel: +98.7132345145, Fax: +98.7132345145, Email: babakdaneshfard@gmail.com

Received: November 16, 2016, Accepted: February 15, 2017, Published: May 2017

iThenticate screening: January 29, 2017, English editing: March, 04, 2017, Quality control: April 12, 2017

(C) 2017 The Authors. This is an open access article under the terms of the Creative Commons Attribution-NonCommercialNoDerivs License, which permits use and distribution in any medium, provided the original work is properly cited, the use is non-commercial and no modifications or adaptations are made. 
addition of ice. It should be sipped slowly and not in haste in a way similar to chewing a morsel. This delay gives the GI system enough time to be prepared for acceptance of water intake, and use it in an appropriate manner; otherwise water could harm the liver and even the central nervous system (CNS) in the passage of time $(8,11)$. Seniors and people who have weak and humid GI tract should use water more cautiously and in smaller amounts. Compared to healthy young people, the interval between the time of eating a meal and drinking water should be longer (9). Patients with gastroesophageal reflux disease (GERD) or other GI problems who suffer from reflux, night drooling, and/or weak digestion may feel better if they observe the aforementioned rules of drinking water. Avoiding watery and juicy foods accompanied with TPM measures' observance will decrease their annoying symptoms and improve their disease (11).

Based on our knowledge and clinical experiences, observing TPM measures attributed to eating and drinking, is beneficial and makes patients and even healthy people feel better in their life; however, scientific confirmation of these rules and putting them into practice needs scrutinized and well-designed multicenter clinical experiments, similar to those initiated in the TPM department of Shiraz University of Medical Sciences.

\section{Acknowledgments:}

Nothing to declare.

\section{Conflict of Interest:}

There is no conflict of interest to be declared.

\section{Authors' contributions:}

$\mathrm{MN}$ contributed in the main idea of the paper, data gathering and writing the draft. $\mathrm{BD}$ wrote the final version of the article.

\section{References:}

1) Nimrouzi M, Zare M. Principles of Nutrition in Islamic and Traditional Persian Medicine. J Evid Based Complementary Altern Med. 2014; 19(4): 267-70. doi: 10.1177/2156587214542006. PMID: 25027179.

2) Daneshfard B, Dalfardi B. Medieval roots of modern knowledge regarding carotid sinus syncope. Int J Cardiol. 2014; 173(2): 342-3. doi: 10.1016/j.ijcard.2014.03.030. PMID: 24679687.

3) Nimrouzi M, salehi A, Ahmadi A, Kiani H. Avicenna's medical didactic poems: Urjuzehtebbi. Acta Med Hist Adriat. 2015; 13(Suppl 2): 45-56. PMID: 26959631.

4) Siahpoosh M, Ebadiani M, Hosseini GRS, Isfahani M, Nasrabadi AN, Dadgostar H. Avicenna the first to describe diseases which may be prevented by exercise. Iran J Public Health. 2012; 41(11): 98-101. PMID: 23304683. PMCID: PMC3521893.

5) Moradi H, Minaii B, Nikbakht Nasrabadi A, Siahpoosh MB. Avicenna viewpoint about health preservation through healthy nutrition principles. Iran J Public Health. 2013; 42(2):220-1. PMID: 23513187, PMCID: PMC3595654.

6) Nimrouzi M, Zarshenas MM. Holistic approach to functional constipation: Perspective of traditional Persian medicine. Chin J Integr Med. 2015. doi: 10.1007/s11655-015-2302-3. PMID: 26597285.

7) Bell E, Acarregui M. Restricted versus liberal water intake for preventing morbidity and mortality in preterm infants. Cochrane Database Syst Rev. 2001; (3): CD000503. doi: 10.1002/14651858.CD000503. PMID: 11686962.

8) Avicenna H. Ghanoon Dar Teb [The Canon of Medicine], Bulaq Edition. Sharafkandi A, trans Tehran: Univ of Tehran Pr. 1978.

9) Nimrouzi M, Zarshenas MM. Management of anorexia in elderly as remarked by medieval Persian physicians. Acta Med Hist Adriat. 2015; 13(Suppl 2): 115-28. PMID: 26959636.

10) Siahpoosh MB, Nejatbakhsh F. Avicenna aspect of cardiac risk factors. Iran J Public Health. 2013; 42(7): 787-8. PMID: 24455496, PMCID: PMC3881626.

11) Pasalar M, Nimrouzi M, Choopani R, Mosaddegh M, Kamalinejad M, Mohagheghzadeh A, et al. Functional dyspepsia: A new approach from traditional Persian medicine. Avicenna J Phytomed. 2016; 6(2): 165-74. PMID: 27222829, PMCID: PMC4877961. 